\title{
SURFACTANT-ENHANCED ALKALINE FLOODING \\ WITH WEAK ALKALIS
}

Topical Report

NIPER- -507

By

DE91 002227

T. R. French

C. B. Josephson

February 1991

Work Performed Under Cooperative Agreement No. FC22-83FE60149

\author{
Prepared for \\ U.S. Department of Energy \\ Assistant Secretary for Fossil Energy
}

Thomas B. Reid, Project Manager

Bartlesville Project Office

P.O. Box 1398

Bartlesville, OK 74005

MASIER

\author{
Prepared by \\ IIT Research Institute \\ National Institute for Petroleum and Energy Research \\ P. O. Box 2128 \\ Bartlesville, OK 74005
}




\section{TABLE OF CONTENTS}

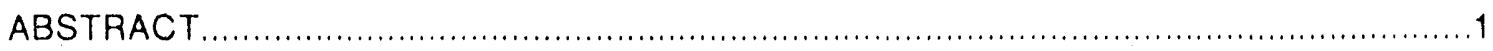

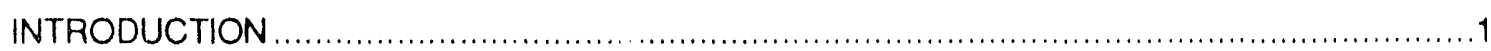

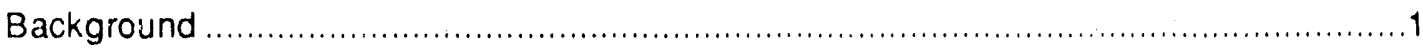

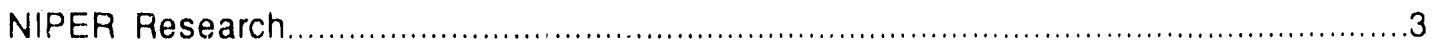

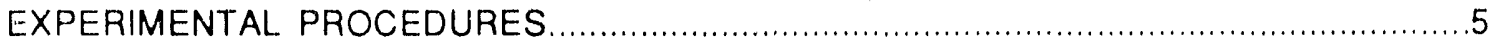

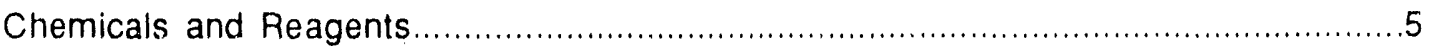

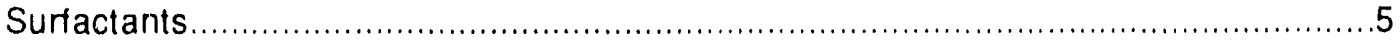

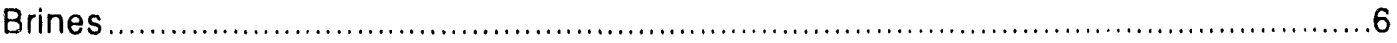

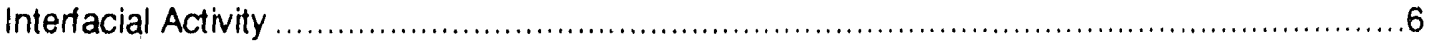

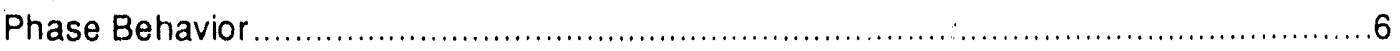

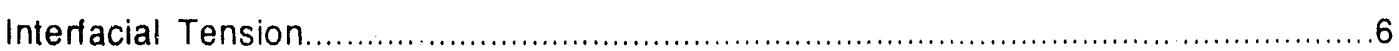

Oil Displacement Tests..............................................................................

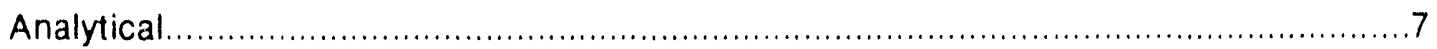

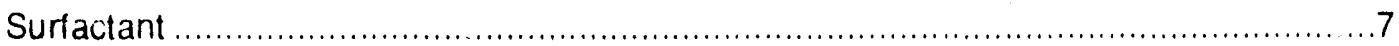

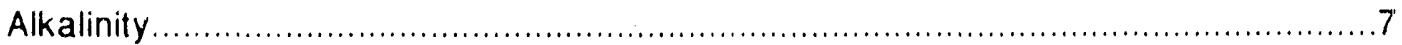

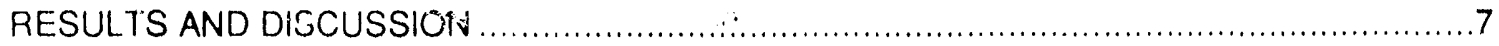

Alkaline-Surfactant Flooding, Application to Oils with Low Acid Content ......................... 7

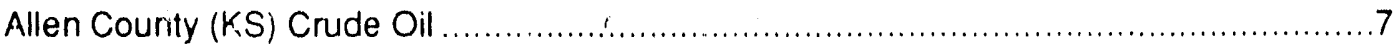

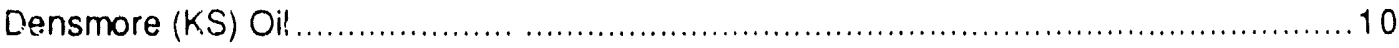

Alkali-Surfactant Flooding, an Oil with High Acid Content ..................................... 13

Effects of Wionohydrogen Phosphate Ion Species on IFT and Adsorption..................... 17

Surfactant Transport in Porous Media.................................................................... 19

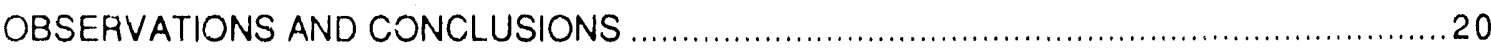

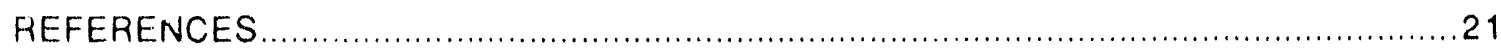

\section{TABLES}

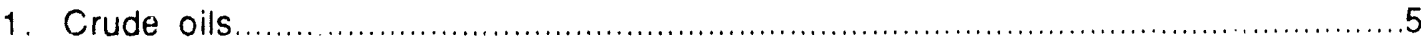

2. Surfactant-enhanced alkali corefloods..................................................... 11

3. Effect of monohydrogen phosphate $\left(\mathrm{HPO}_{4}=\right)$ on the IFT of Wilmington crude oil and weakly alkaline surfactant mixtures, $0.1 \%$ Petrostep B-100 surfactant, pH 10.5 ......... 18

4. Effect of monohydrogen phosphate $\left(\mathrm{HPO}_{4}=\right)$ on the adsorption of Petrostep B-100 surfactant in weakly alkaline mixtures, $\mathrm{pH} 9.5$ 


\section{ILLUSTRATIONS}

1. Dynamic interfacial tension of Allen Co. (KS) crude oil and $0.1 \%$ Petrostep B-100 surfactant, $30^{\circ} \mathrm{C}$

2. Dynamic interfacial tension of Allen Co. (KS) crude oil and $0.1 \%$ Petrostep B-100 surfactant, $\mathrm{pH} 9.5,52^{\circ} \mathrm{C}$......

3. Interfacial tension of Densmore (KS) crude oil and $0.1 \%$ Petrostep B-100 surfactant, $\mathrm{pH} 9.5,52^{\circ} \mathrm{C}$

4. Interfacial tension of Densmore (KS) crude oil and $0.1 \%$ Neodol 25-9 surfactant, $\mathrm{pH} 9.5,52^{\circ} \mathrm{C}$ 12

5. Results of chemical flood DEN-1. .13

6. Dynamic IFT of Wilmington (CA) Ranger Zone crude oil, $\mathrm{pH} 9.5$. 14

7. Dynamic IFT of Wilmington (CA) Ranger Zone crude oil and $0.1 \%$ Neodol $25-9$ surfactant 15

8. Interfacial tension of Wilmington (CA) Ranger Zone crude oil and $0.1 \%$ Igepon T-33 surfactant, $\mathrm{pH} 8.3,52^{\circ} \mathrm{C}$.

9. Interfacial tension of Wilmington (CA) Ranger Zone crude oil and $0.1 \%$ CA-720 surfactant, $\mathrm{pH} 8.3,52^{\circ} \mathrm{C}$.

10. Surfactant transport in an oil-free Berea sandstone 


\title{
SURFACTANT-ENHANCED ALKALINE FLOODING WITH WEAK ALKALIS
}

By Troy French and Charles Josephson

\begin{abstract}
The objective of Project BE4B in FY90 was to develop cost-effective and efficient chemical flooding formulations using surfactant-enhanced, lower $\mathrm{pH}$ (weak) alkaline chemical systems. Chemical systems were studied that mitigate the deleterious effects of divalent ions. The experiments were conducted with carbonate mixtures and carbonate/phosphate mixtures of $\mathrm{pH} 10.5$, where most of the phosphate ions exist as the monohydrogen phosphate species. Orthophosphate did not further reduce the deleterious effect of divalent ions on IFT behavior in carbonate solutions, where the deleterious effect of the divalent ions is already very low. When added to a carbonate mixture, orthophosphate did substantially reduce the adsorption of an anionic surfactant, which was an unexpected result; however, there was no correlation between the amount of reduction and divalent ion levels.
\end{abstract}

For acidic oils, a variety of surfactants are available commercially that have potential for use between $\mathrm{pH} 8.3$ and $\mathrm{pH}$ 9.5. Several of these surfactants were tested with oil from Wilmington (CA) field and found to be suitable for use in that field. Two low-acid crude oils, with acid numbers of 0.01 and $0.27 \mathrm{mg} \mathrm{KOH} / \mathrm{g}$ of oil, were studied. It was shown that surfactant-enhanced alkaline flooding does have merit for use with these low-acid crude oils. However, each $h y$-acid oil tested was found to behave differently, and it was concluded that the applicability of the method must be experimentally determined for any given low-acid crude oil.

\section{INTRODUCTION}

\section{Background}

In the United States, numerous oil reservoirs have been waterflooded for many years. It is likely that many of these reservoirs will soun be abandoned unless a cost-effective enhanced oil recovery (EOR) method is discovered. Surfactant-enhanced alkaline flooding, a technology developed fairly recently, is a potentially cost-effective method for recovery of much of this oil.

Initial investment costs for purchasing chemicals for injected formulations have been a significant economic disincentive that has hindered commercial applications of many chemical flooding technologies. Surfactant-enhanced alkaline flooding formulations are potentially more cost-effective than some other flooding methods because the cost of the alkaline chemicals is low. The key to obtaining favorable economics is a synergism between alkali, surfactant, and oil that results in mobilization of some crude oils 
at greatly reduced surfactant concentrations. Another favorable property of surfactant-enhanced alkaline systems is reduced loss of surfactant onto reservoir rock by precipitation and adsorption.

Alkaline agents such as sodium hydroxide and sodium orthosilicate, which increase $\mathrm{pH}$ values to greater than 12, are able to extract surface-active componenis from certain crude oils and produce ultralow interfacial tensions that result in efficient oil mobilization. However, such formulations are also frequently reactive with reservoir rocks, particularly those containing clay minerals. Oils with high acid contents are especially amenable to conventional alkaline flooding, and a number of field tests have been conducted in California to recover heavy oils with high acid content. Most of these field tests using conventional alkaline flooding methods were disappointing. A recent study of 24 alkaline flooding field projects indicated that one-third of the projects experienced problems caused by scale formation. ${ }^{1}$ The reaction of high $\mathrm{pH}$ (strong) alkalis with reservoir rocks causes loss of effectiveness of the injected alkaline slug and dissolution of ions that can cause deposition of mineral scales at producing wells.

Fundamental research on reaction kinetics of alkaline formulations with reservoir minerals has indicated that it is impossible to prevent the deleterious reactions that occur with highly alkaline chemical formulations in most reservoir formations. This work led to investigations of milder alkaline agents that are less reactive with reservoir rocks. Initial studies on formulations using sodium carbonate and sodium bicarbonate indicated that the displacement efficiency was much less with certain crude oils than that obtainable with highly alkaline chemicals such as sodium hydroxide and sodium orthcsilicate. Fundamental research on coalescence phenomena and dynamic interfacial tension behavior indicated that addition of small amounts of suriactants to moderately alkaline formulations significantly improved the properties of the system. The efficacy of these surfactant-enhanced alkaline flooding formulations :vas subsequently verified in oil displacement tests in cores.

The recent activity in alkaline flooding has been in Wyoming, Louisiana, and Texas. Initial results from field tests that were conducted with surfactant-erihanced alkaline formulations are promising. In White Castle (LA) Field, Shell Oil Co. applied an alkaline formulation that contained sodium carbonate, sodium silicate, internal olefin sulfonate, and alcohol ethoxylate. ${ }^{2}$ Sodium silicate was included to reduce silica dissolution. West Kiehl field in the Minelusa Trend of Wyoming was the site of a test conducted with 0.25 PV of $0.8 \%$ sodium carbonate, $0.1 \%$ pelroleum sulfonate, and polymer. Production reportedly increased trom 37 to $580 \mathrm{bbl} / \mathrm{d}^{3}$

A test by Belco Petroleum Company of sodium carbonate flooding (without surfactant enhancement) in the Isenhour Unit, Wyoming was reported as successful. ${ }^{1}$ Dome Petro: ?um Ltd. is 
conducting a similar sodium carbonate flood in Lloydminster A field in southeast Alberta. ${ }^{4}$ Positive results from these field tests should increase the credibility of alkaline flooding.

It has been shown that surfactant-enhanced alkaline flooding formulations with weak alkaline agents have great potential. These alkaline formulations react less with reservoir minerals and facilitate the use of low concentrations of surfactants because surfactant adsorption is reduced in the presence of alkaline agents. Moderately basic alkaline chemicals, such as sodium carbonate and sodium bicarbonate, are also effective for mobilizing residual oil when relatively low concentrations of surfactant are added to the formulation.

\section{NIPER Research}

The objective of Project BE4B in FY90 was to develop cost-effective and efficient chemical flooding formulations using surfactant-enhanced, lower $\mathrm{pH}$ (weak) alkaline chemical systems. It has been shown previously that these chemical systems can be effective in mobilizing residual oil when relatively low concentrations of surfactant are used in the formulation. The specific objectives for FY90 were (1) to investigate the applicability of alkaline-surfactant flooding to reservoirs containing low-acid-content crude oils, (2) to test commercially available EOR chemicals that could be used in pilot alkaline floods conducted in fields that contain an acidic oil, and (3) to study chemical systems that are expected to mitigate the deleterious effects of divalent ions.

Several years ago, NIPER began testing weak alkaline agents, such as sodium bicarbonate and sodium carbonate, for their ability to mobilize residual oil. The use of weak alkalis was shown to avoid or reduce some of the adverse reactions that usually occur between reservoir rock and the strong alkalis. The lower pH alkalis reacted with acidic components of crude oils to produce surfactants in situ, but the amounts of the natural surfactants extracted from the crude oil were less than that obtained with stronger alkaline agents. Therefore, the reduction in IFT was also less.

During attempts to increase the amount of oil solubilized, it was discovered that very low concentrations of synthetic surfactants could be added to the alkaline slug and be very effective in oil recovery. ${ }^{5}$ It was also observed that alkaline conditions resulted in lower losses of surfactant by precipitation and adsorption. Most of the research was conducted with heavy oils that contained significant amounts of acidic components. In these experiments, the total acid number, which is an indication of the amount of acidic components in an oil, was usually above $1.0 \mathrm{mg} \mathrm{KOH} / \mathrm{g}$ of oil. During the

initial work, it was assumed that an appreciable acid number would be necessary for alkaline additives to have a significant impact on the lowering of IFT by a surfactant formulacion. It was concluded, however, 
that some of the other effects of alkaline additives would be beneficial in reservoirs that contain non-acidic oils.

Studies with an acidic oil and surfactantalkaline formulations showed that a very low initial IFT was predominantly the result of natural surtactants generated by reaction with alkaline agents, and sustained low IFT was primarily the result of synthetic surfactant. ${ }^{6}$ A mixture of synthetic surfactant and alkali produced low IFT and sustained low IFT longer than either reactant alone. It was also observed that the extraction of acids from acidic crude oils by alkalis appears to render the oil more interfacially reactive to synthetic surfactant. A detailed study of 24 alkaline field projects failed to show a correlation between oil acid number and project success. ${ }^{1}$ These observations led to tests in FY90 with heavy oils that have low acid numbers. The extension to non-acidic and slightly acidic oils is not obvious. If surfactant-enhanced alkaline flooding methods can be applied to recover crude oils with low acid content, then the target resource for this technology is greater than previously thought. One of the objectives of the project was to investigate the applicability of surfactant-enhanced alkaline flooding to oils that have low acid content.

The research program was also focused on application of surfactant-enhanced alkaline technology. Therefore, to accomplish the second objective of this project, the testing of several surfactants that are available commercially at competitive prices was undertaken. Since crude oils that have appreciable acid content are the most likely candidates for surfactant-enhanced alkaline flooding, focus was on target reservoirs that contain heavy, acidic crude. Wilmington field was selected as the principal target reservoir because it is the largest oil field in California, the crude oil is highly acidic and particularly amenable to alkaline flooding, and it was viewed as being representative of a significant number of heavy oil reservoirs in California. Development efforts were focused on design of surfactant-enhanced alkaline flooding formulations for the Ranger zone of Wilmington field. Previously, surfactant-enhanced flooding formulations were optimized with synthetic surfactants and carbonate mixtures. The FY90 goal was to develop a formulation that contained a commercially available surfactant and sodium bicarbonate.

Some alkaline agents provide protection from loss for the low-concentration surfactant used in surfactant-enhanced alkaline flooding. Alkaline agents such as sodium carbonate remove many, but not all, of the divalent ions from reservoir brine. However, divalent ion removal is not complete, especially for magnesium ions. ${ }^{7}$ Therefore, additional means of protecting anionic surfactants from deleterious precipitation reactions with calcium and magnesium ions are desirable. It has long been recognized that certain chemical agents can reduce the activity of divalent cations. Polyphosphates and organic chelating agents have been used for this purpose. ${ }^{8-9}$ 
All phosphates, including orthophosphate, are highly charged and will associate with cations in solution. In addition to simple ion association, there is a tendency to form covalent bonds between phosphate groups and cations. The complexation that occurs is due to both ionic and covalent contributions to the overall bond. ${ }^{10-11}$ In FY89, it was determined that low levels of calcium ions had little or no detrimental effect on the dynamic IFT behavior of surfactant-enhanced alkaline formulations that contained monohydrogen phosphate. ${ }^{12}$ The thind objective for FY90 was to extend the previous study of chemical systems that are expected to mitigate the deleterious effects of divalent ions.

This report is divided into four sections that are organized according to the project objectives. Sections 1-3 correspond to project objectives 1-3, which were described above. Section 4 relates to the transport of surfactant through porous media and is a continuation of work started in FY89.

\section{EXPERIMENTAL PROCEDURES}

\section{Chemicals and Beagents}

The crude oils were selected according to the oil properties required to meet project objectives. To investigate the applicability of alkaline-surfactant flooding to reservoirs with low-acid-content crudes, two crude oils were used. One of these oils was obtained from the Bartlesville sand in Allen County, Kansas, and the other from the Reagan sand in Norton County, Kansas (Densmore field). The tests with commercially available EOR chemicals were conducted with an acidic crude oil from Wilmington (CA) oil field. Crude oil properties are summarized in table 1.

TABLE 1. - Crude oils

\begin{tabular}{lcccc}
\hline Oil & $\begin{array}{c}\text { Total acid number, } \\
\mathrm{mg} \mathrm{KOH} / \mathrm{g}\end{array}$ & Gravity, ${ }^{\circ} \mathrm{API}$ & $\begin{array}{c}\text { Reservoir } \\
\text { temperature, }{ }^{\circ} \mathrm{C}\end{array}$ & $\begin{array}{c}\text { Productive } \\
\text { zones }\end{array}$ \\
\hline Wilmington (CA) & 1.59 & 18.0 & 52 & Ranger \\
Densmore (KS) & 0.27 & 19.8 & 45 & Reagan Sand \\
Allen (KS) & 0.01 & 20.2 & 22 & Bantlesville Sand \\
\hline
\end{tabular}

\section{Surfactants}

Petrostep B-100, a medium-molecular-weight alkyl aryl sodium sulfonate produced by Stepan Company, was used for most of the experiments conducted with low-acid-content crudes. It is designed for use in low-concentration surfactant flooding, and the maximum concentration used for the 
experiments was $0.2 \%$ active. Several other surfactants produced by GAF Chemical Company and Shell Chemical Company were used for phase behavior and IFT experiments conducted with the Wilmington oil.

\section{Brines}

The synthetic brines contained sodium chloride. The alkaline additives were sodium bicarbonate and mixtures of sodium bicartonate with sodium carbonate. Calcium chloride or magnesium chloride was added to the brine in order to stuty the effects of divalent ions on dynamic IFT and adsorption.

\section{Interfaclal Actleity}

\section{Phase Behavior}

Equil volumes $(4 \mathrm{~mL})$ of oil and aqueous phase were sealed in $10-\mathrm{mL}$ graduated ampoules, and the samples were placed in a temperature-controlled oven. Observations were made after 1 day. The samples were observed at that time and evaluated. The samples were then evaluated while being shaken. Finally, the samples were evaluated again after 1 more day. The observation while shaking provided information about the type of emulsion formed (oil-in-water or water-in-oil), the ease of emulsification, the stabiliiy of the emulsion (while shaking), and the amount (qualitative) of oil emulsified. The final evaluation ( 1 day after shaking) provided additional data on emulsion stability.

The emulsions formed were evaluated according to the following criteria:

\section{Emulsion quality}

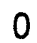

1

2

3

4

\section{Criteria}

No visual emulsification.

Black emulsion.

Brown emulsion that changes to black while shaking.

Brown emulsion.

Brown emulsion containing $>90 \%$ of the oil in the sample.

Higher values of "emulsion quality" correlate with greater interfacial activity and nearness to optimal cunditions. This visual method for determining optimal salinity for producing interfacially active systems is only slightly different from the visual methods that are used by others. ${ }^{13-14}$

\section{Interfacial Tension}

Interfacial properties of selected systems were measured with a controlled temperature spinning drop interfacial tensiometer. The transient IFT behavior of non-equilibrated samples was monitored over a time interval of several hours. 


\section{Oll Displacement Tests}

Unfired, oil-free Berea cores $(25.4 \times 3.8 \mathrm{~cm})$ were saturated with brine and mounted in Hassler-type coreholders. The cores were oil flooded to residual water saturation and then waterflooded to residual oil saturation before starting the chemical flood. Frontal advance rates were approximately $1 \mathrm{ft} / \mathrm{d}$, providing a core residence time of about 0.8 day.

\section{Analytical}

\section{Surfactant}

The analytical methods used for measurement of surfactant concentration were two-phase titration and HPLC. The two-phase titration was described by Rosen and Goldsmith, ${ }^{15}$ and the HPLC procedure is very similar to that described by Hofman and Angstadt. ${ }^{16}$ The wavelength used for absorbance measurement of Petrostep B-100 surfactant was $222 \mathrm{~nm}$, which is very close to the wavelength selected by Hofman and Angstadt.

\section{Alkalinity}

Effluent samples were collected in $5-\mathrm{ml}$ increments and centrifuged before the volume of oil collected was determined. The aqueous phase was then separated and analyzed for alkalinity by titration to $\mathrm{pH} 4$ with $0.1 \mathrm{~N} \mathrm{HCl}$.

\section{RESULTS AND DISCUSSION}

\section{Alkaline-Surfactant Flooding. Application to Olls With Low Acid Content}

Prior work has shown that the acidic content of a crude oil, which is usually expressed as acid number, is not necessarily a reliable indicator of how amenable an oil is to alkaline flooding. ${ }^{1}$ If surfactantenhanced alkaline flooding methods can be applied to recover crude oils with low acid content, then the target resource for this technology would be greater than was previously thought.

\section{Allen County (KS) Crude Oll}

Dynamic interfacial tension (IFT) experiments were performed with crude oil from the Bartlesville sand in Allen County, Kansas. This oil has a total acid number (TAN) that is near zero $(0.01 \mathrm{mg} \mathrm{KOH} / \mathrm{g}$ oil). The purpose of the experiments was to separate the effects of weak alkali and surfactant in interfacial tension reduction when using a very low TAN crude oil. The experiments were performed with an anionic Surfactani (Petrostep B-100) that is sparingly soluble at the upper range of ionic strength values of the mixtures tested. The $\mathrm{pH}$ of the test solutions was either unadjusted (about pH 6.3) or pH 9.5. Adjustment of $\mathrm{pH}$ was accomplished with an appropriate carbonate mixture. Total calculated ionic strength of the 
mixtures ranged from $0-0.748$. The actual ionic strength values for the carbonate mixtures may vary from the calculated values due to equilibrium reactions between the carbonate ion species.

The effect of the carbonate mixture on IFT was tested over a broad range of ionic strengths, 0.234 10 0.648 . All of the IFT values obtained with the oil and carbonate mixtures were above $10 \mathrm{mN} / \mathrm{m}$. These results were not unexpected, since the very low TAN of the oil should result in very low reactivity to weak alkali.

IFT measurements were also conducted using a low concentration $(0.1 \%)$ of surfactant and ionic strengths from $0.051(0.3 \% \mathrm{NaCl})$ to $0.510(3.0 \% \mathrm{NaCl})$. Because of solubillty limitations, the IFT of this surfactant was not measurable in the $3 \% \mathrm{NaCl}$ solution. The results are shown in figure 1 . The best results with the $\mathrm{pH} 6.3$ (pH unadjusted) surfactant mixture were obtained at ionic strengths of $0.205(1.2 \%$ $\mathrm{NaCl}$ ) and $0.410(2.4 \% \mathrm{NaCl})$. In $2.4 \% \mathrm{NaCl}$, the transient IFT was very slowly reduced over a period of 169 minutes from an initial IFT of $773 \mu \mathrm{N} / \mathrm{m}$ to an equilibrium value of $306 \mu \mathrm{N} / \mathrm{m}$ after 169 minutes.

Figure 1 also shows the transient IFT behavior of the suffactant mixture at $\mathrm{pH} 9.5$. The ionic strength of the $\mathrm{pH} 9.5$ carbonate mixtures is 0.238 (no added salt) and 0.289 (in $0.3 \% \mathrm{NaCl}$ ). In the figure, it can be seen that the IFT values of the surfactant in weak alkali are much lower than that for similar ionic strength surfactant mixtures that do not contain alkali. At pH 9.5 and ionic strength 0.238 (no added salt), the initial IFT value was $202 \mu \mathrm{N} / \mathrm{m}$, and this decreased to an equilibrium value of $86 \mu \mathrm{N} / \mathrm{m}$ after 44 minutes. Increasing the ionic strength to 0.289 with added salt caused slightly higher IFT values. All of these experiments were performed at $30^{\circ} \mathrm{C}$, which is near reservoir temperature.

IFT experiments were also periormed at $52^{\circ} \mathrm{C}$ with the same crude oil and weak alkali at similar ionic strengths. Those results are shown in figure 2. At the higher temperature, lower IFT values were obtained from 0.289 (alkali in $0.3 \% \mathrm{NaCl}$ ) to 0.409 (alkali in $1.0 \% \mathrm{NaCl}$ ) values of ionic strength. This effect of increasing temperature yielding lower initial IFT values and lower equilibrium IFT values has been observed with other slightly acidic crude oils and alkali/surfactant mixtures. ${ }^{17}$

The conclusion drawn from these results is that low, but not necessarily ultralow, IFT values can be obtained with slightly acidic crude oils and mixtures that contain dilute concentration of surfactant under weakly alkaline conditions. Furthermore, the IFT obtained under alkaline conditions is lower than the IFT obtained with surfactant alone or alkali alone. The conditions studie , over a broad ra ige of ionic strengths. 


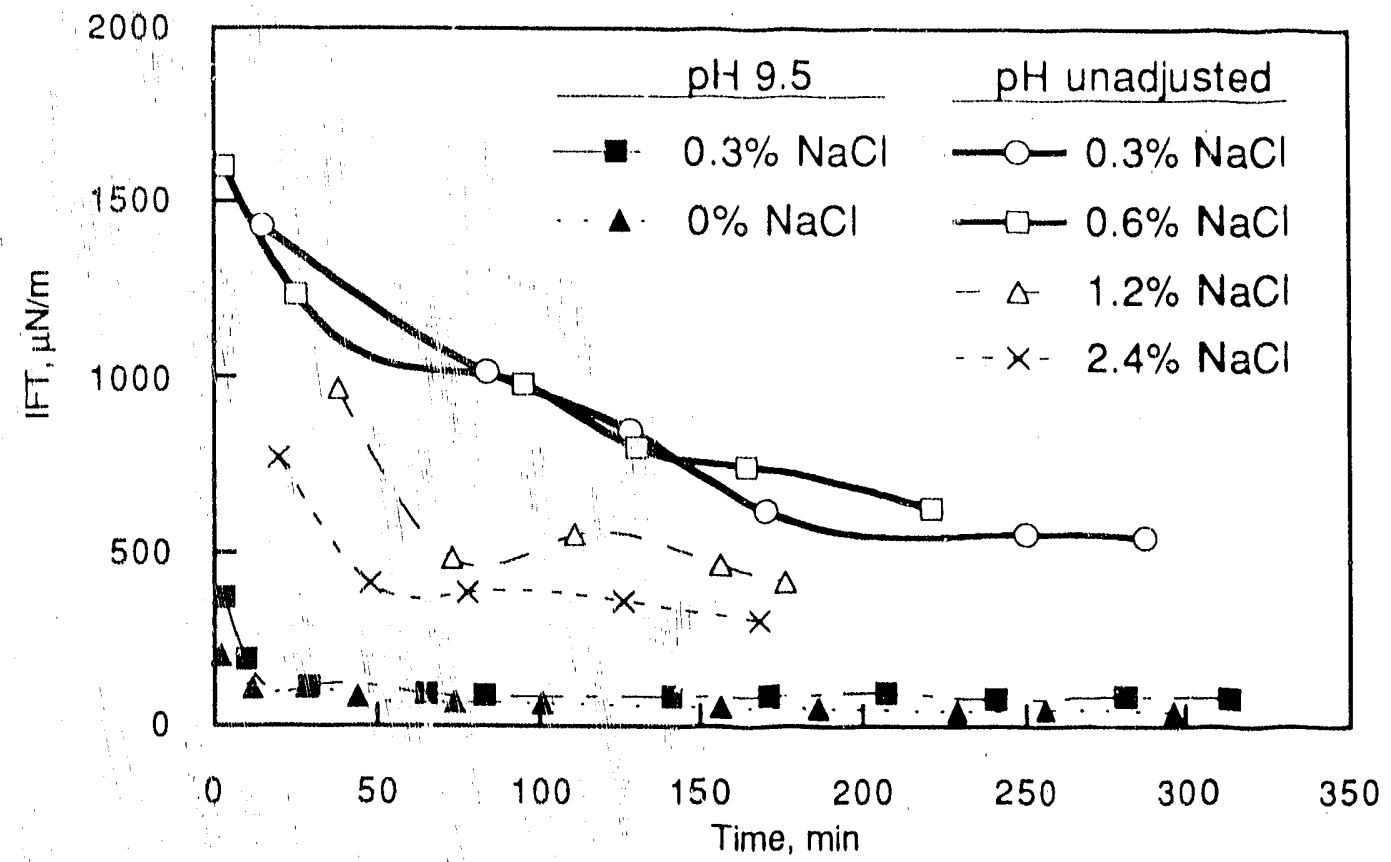

FIGURE 1. Dynamic interfacial tension of Allen Co. (KS) crude oil and $0.1 \%$ Petrostep B-100 surfactant, $30^{\circ} \mathrm{C}$.

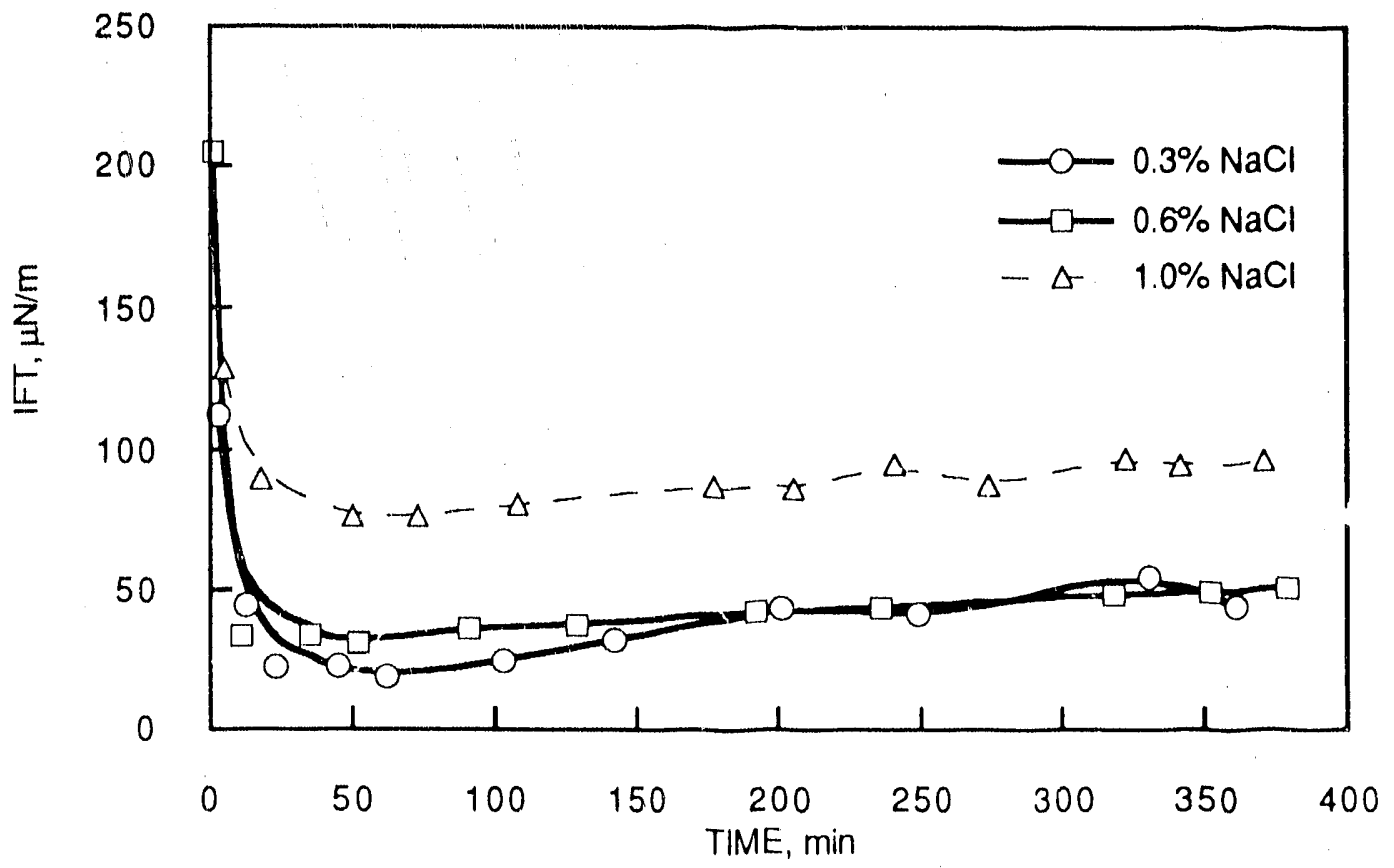

FIGURE 2. Dynamic interíacial tension of Allen Co. (KS) crude oil and $0.1 \%$ Petrostep B-100 surfactant, $\mathrm{pH} 9.5,52^{\circ} \mathrm{C}$. 
These chemical systems were also used in oil recovery tests. The results are shown in table 2 (corefloods WILS-1, WILS-2, and WILS-3). None of the chemical systems produced IFT values below $20 \mu \mathrm{N} / \mathrm{rn}$, and the incremental oil produced was only $18.5 \pm 2.3 \%$ of the sil that remained at:er waterflooding.

\section{Deirsmore (KS) Oll}

Phase behavior iests and dynamic IFT measurements were conducted with oil from Densmore (KS) field. This oil has a low acid conteni (total acid number $=0.27 \mathrm{mg} \mathrm{KOH} / \mathrm{g}$ oil). The purprse of the experiments was to determine if a surfactant-enhanced alkaline flooding formulation is useful for recovery of an oil which has an appreciable, but yet low, acid content. Two commercial surfactants were tested. The $\mathrm{pH}$ was maintained at $\mathrm{pH} 9.5$ with a cartonate mixture.

One series of experiments was conducted at pH 9.5 with $0.1 \%$ acılve anionic surfactant (Petrostep B-10C). The IFT over a salinity range is shown in figure 3. Very low IFT values were obtained over the entire salinity range, and this result provided evidence that even low-acid oils will respond favorably to surfactant-enhanced alkaine flooding. It was not possible to predict this IFT behavior froin the results of either the static or aynamic phase behavior tests, because the emulsions that typically indicate low IFT did not form.

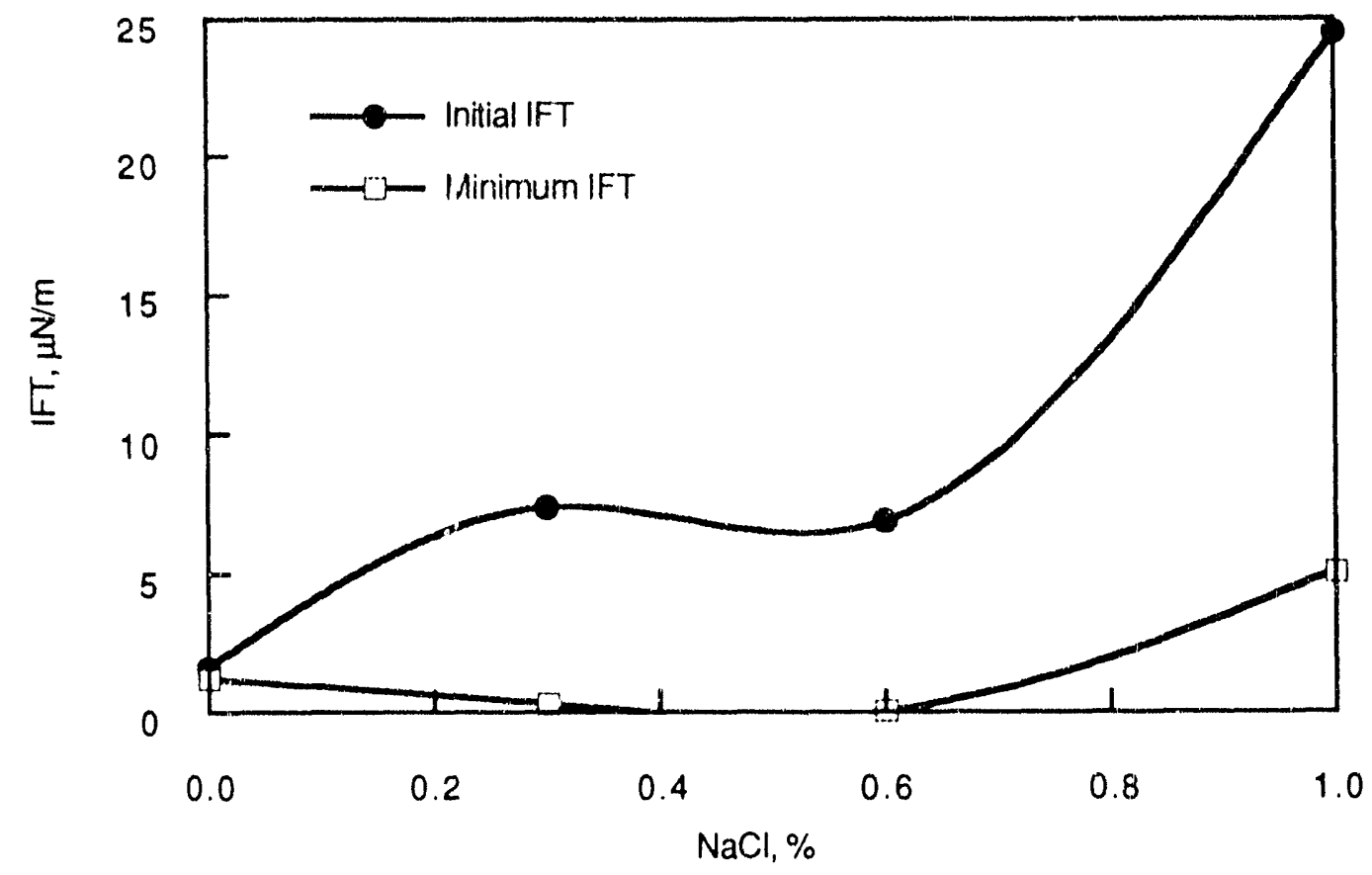

FIGURE 3. interfacial tension of Densmore (KS) crude oil and $0.1 \%$ Petrostep B-100 surfactant, $\mathrm{pH} 9.5,52^{\circ} \mathrm{C}$. 


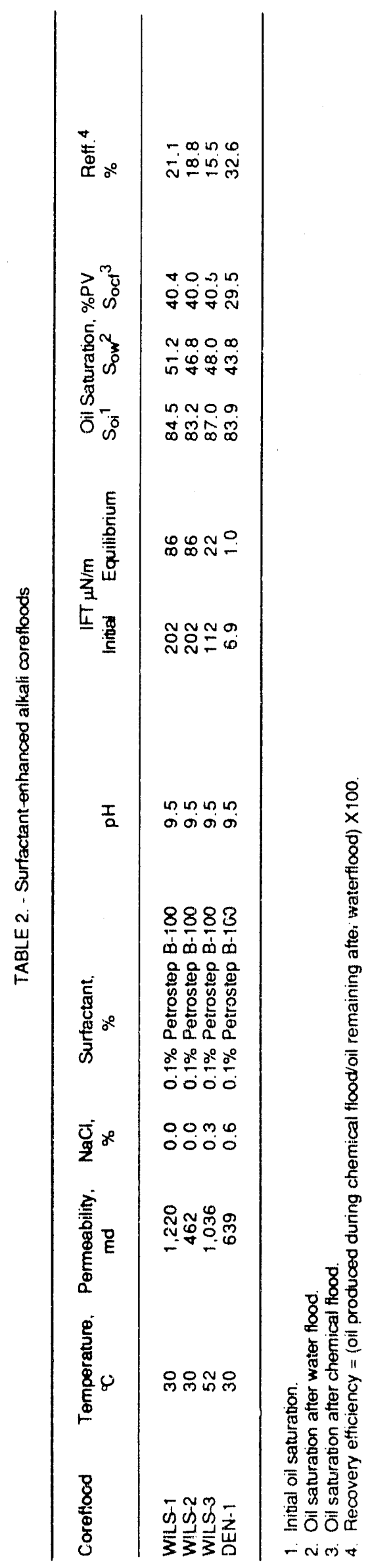


Anothe: pH 9.5 system was formulated with a nonionic surfactant (Neodol 25-9). The IFT over a salinity range is shown in figure 4 . Very low IFT values were measured above $4 \% \mathrm{NaCl}$ concentration. These results were encouraging because traditional high-pH systems produce very low IFT values only at very low salinities. It was not possible to predict this IFT behavior from either static or dynamic phase behavior tests.

The lack of correlation between the phase behavior tests and IFT measurements appears to hold true for medium-pH (i.e. $\mathrm{pH}$ 9.5) alkaline systems when the oil is non-acidic or slightly acidic. The same behavior was also observed when very low $\mathrm{pH}(\mathrm{pH}$ 8.3) surfactant-alkaline systems were tested with acidic oils. Under these conditions, phase behavior testing appears to have little value and IFT measurements must be relied upon for evaluation.

The results of the IFT measurements indicated that surfactant-enhanced alkaline flooding is applicable to this low-gravity, low-acid-number crude oil. This conclusicn was confirmed by the results of an oil recovery test performed using crude oil from Densmore (KS) oil field. The coreflood was conductec with a surfactant-enhanced weakly alkaline system $(\mathrm{pH} 9.5)$. The salinity was $0.6 \% \mathrm{NaCl}$, which was the

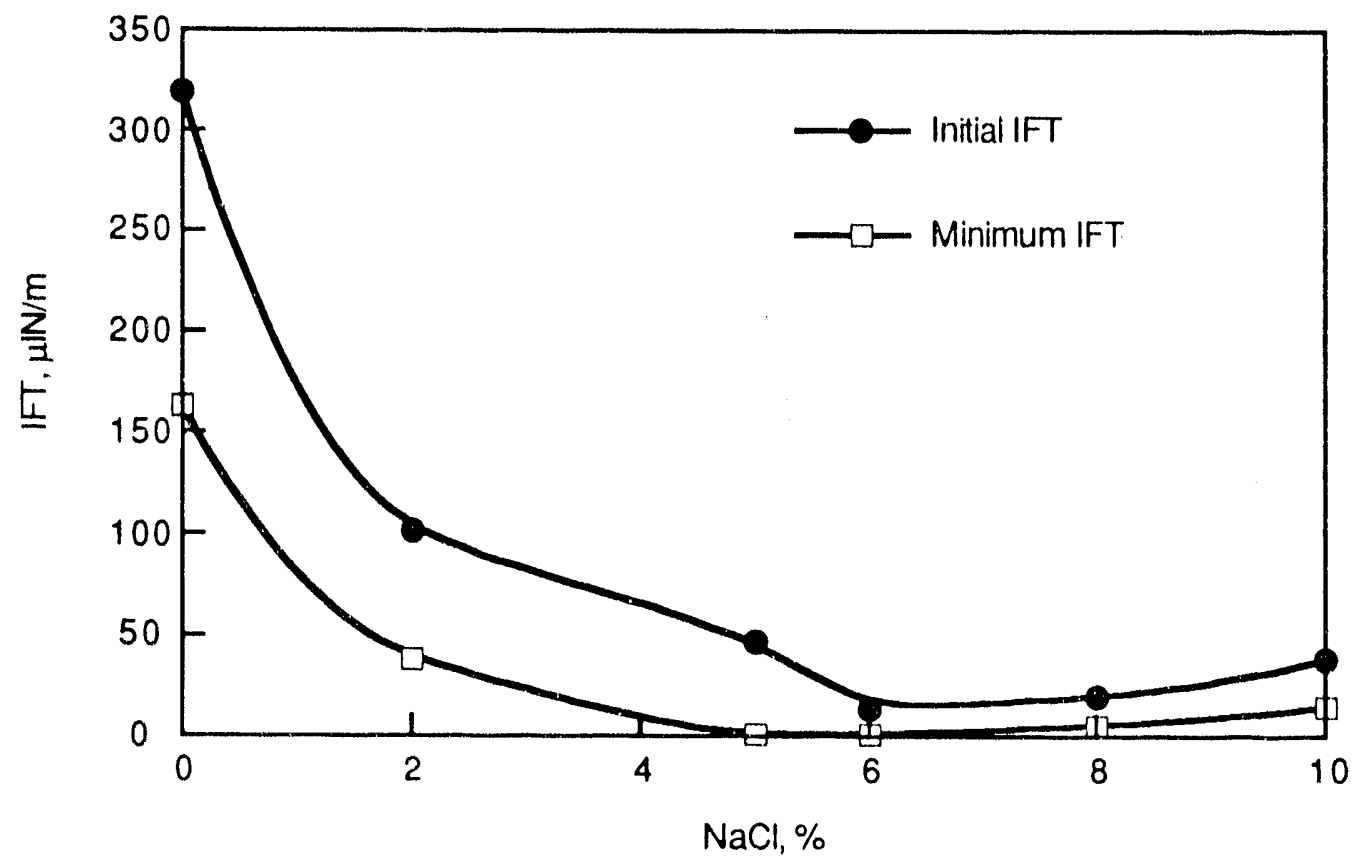

FIGURE 4. Intertacial tension of Densmore (KS) crude oil and $0.1 \%$ Neodol 25-9 surfactant, $\mathrm{pH} 9.5,52^{\circ} \mathrm{C}$. 
optimal salinity for low IFT with the anionic surfactant. The initial IFT between this chemical system and the Densmore crude was $6.9 \mu \mathrm{N} / \mathrm{m}$, which decreased to about $1 \mu \mathrm{N} / \mathrm{m}$ within a few minutes. (See fig. 3.)

A Berea sandstone core was first saturated with crude oil (So $=83.9 \%$ pore volume) and then waterflooded to residual oil saturation (Sowt $=43.8 \%$ ). Chemical flood followed the waterlood and reduced the oil saturation to $29.5 \%$. Figure 5 shows the changes in oil cut and oil saturation that occurred during the chemical flood. The oil recovery efficiency of the chemical flood was $32.5 \%$ of the oil that remained after waterflood.

It was previously believed that a high acid number was essential for alkaline flooding to be successful. These and other resulis ${ }^{18-19}$ that were previously reported indicate that surfactant-enhanced alkaline flooding may also be an effective EOR method with low-acid-content crude oils.

\section{Alkall-Surfactant Flooding, an Oll with Hlah Acld Content}

Weak alkalis often fail to achieve the ultra-low IFT values necessary for significant mobilization of oil. It was discovered in 1985 that the mobilization of acidic oils by weak alkalis could be significantly improved if very small concentrations of synthetic surfactant ware added to the alkaline solutions. ${ }^{6}$ An example of the dynamic IFT behavior of an optimized alkaline system is presented in figure 6 .

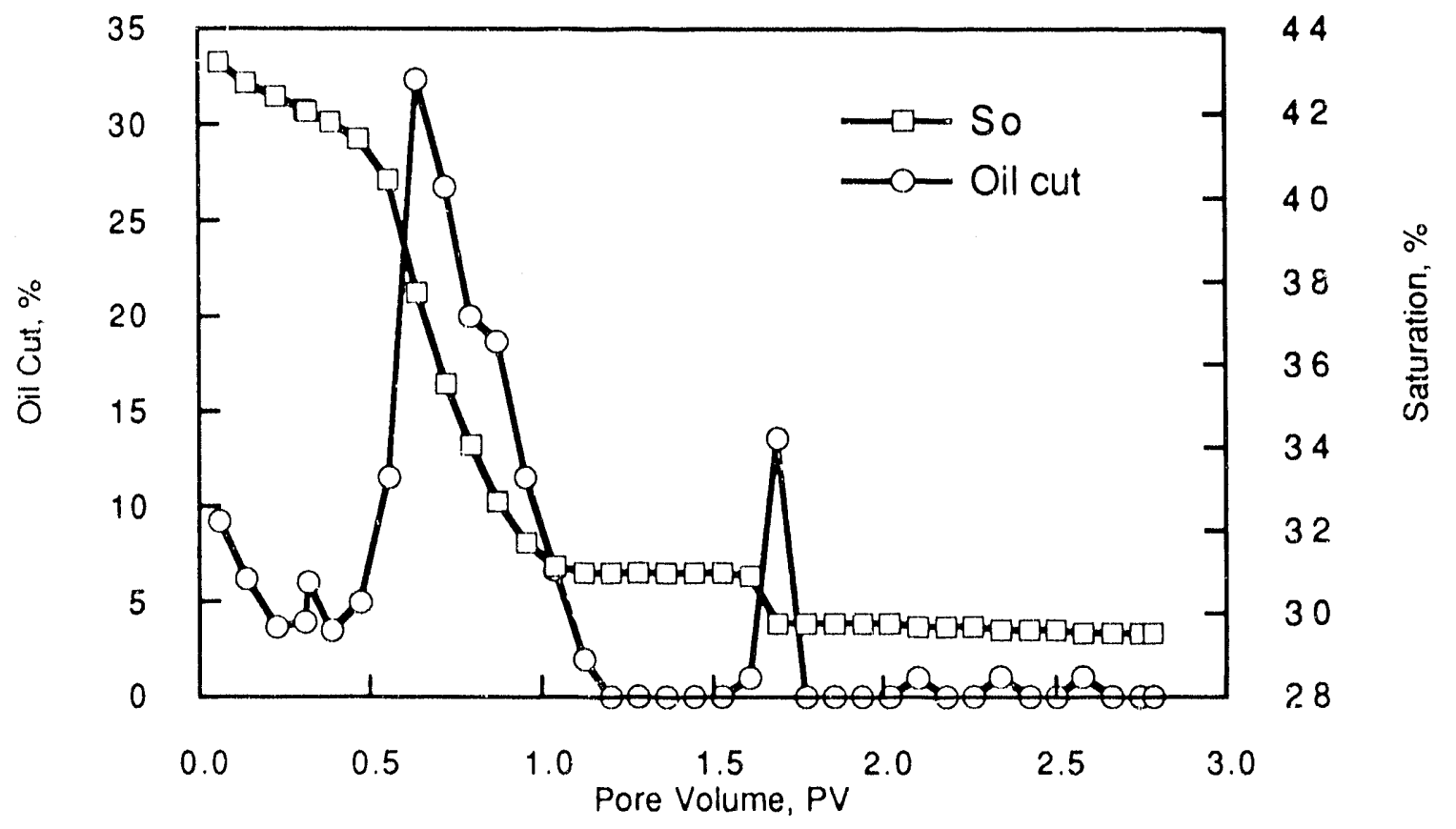

FIGURE 5. Results of chemical flood DEN-1. 


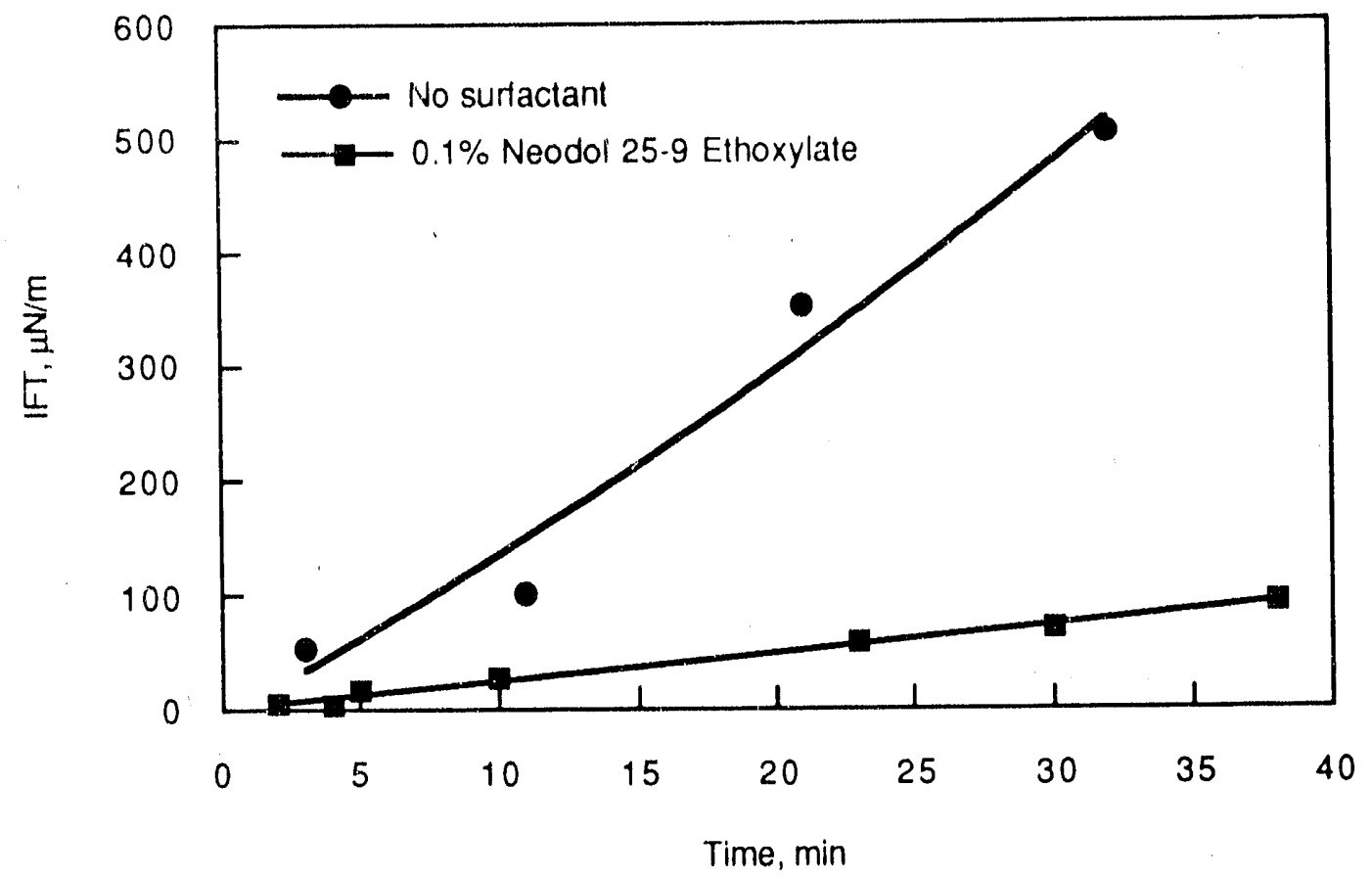

FIGURE 6. Dynamic IFT of Wilmington (CA) Ranger Zone crude oil, pH 9.5.

This example (from FY89 work) is the behavior of a pH 9.5 carbonate mixture that was tested at $52^{\circ} \mathrm{C}$ with oil from the Ranger Zone of Wilmington (CA) field. ${ }^{18}$ The Wilmington crude oil is acidic (table 1) and quite reactive with alkali. Figure 6 shows that alkali causes a very rapid lowering of IFT to $55 \mu \mathrm{N} / \mathrm{m}$ in only 2 minutes; however, IFT begins increasing immediately. Within 32 minutes, IFT increased to $500 \mu \mathrm{N} / \mathrm{m}$.

Whei $0.1 \%$ Neodol $25-9$ alcohol ethoxylate surfactant and alkali were combined (figure 6), the result was a rapid decrease in IFT, followed by a sustained, very slow, increase in IFT. The minimum IFT was $4 \mu \mathrm{N} / \mathrm{m}$ for the combination of surfactant and alkali, much lower than for surfactant (shown in figure 7) or alkali alone. The IFT with the combination of synthetic surfactant and alkali was still below $50 \mu \mathrm{N} / \mathrm{m}$ after 16 minutes.

Similar dynamic IFT behavior was also demonstrated with an anionic surfactant. Since the Wilmington field is very large and the oil is particularly amenable to alkaline flooding, this field is a principal target for alkaline flooding projects. Therefore, it was considered desirable to test several other commerciaily available surfactants for possible use in this field. 


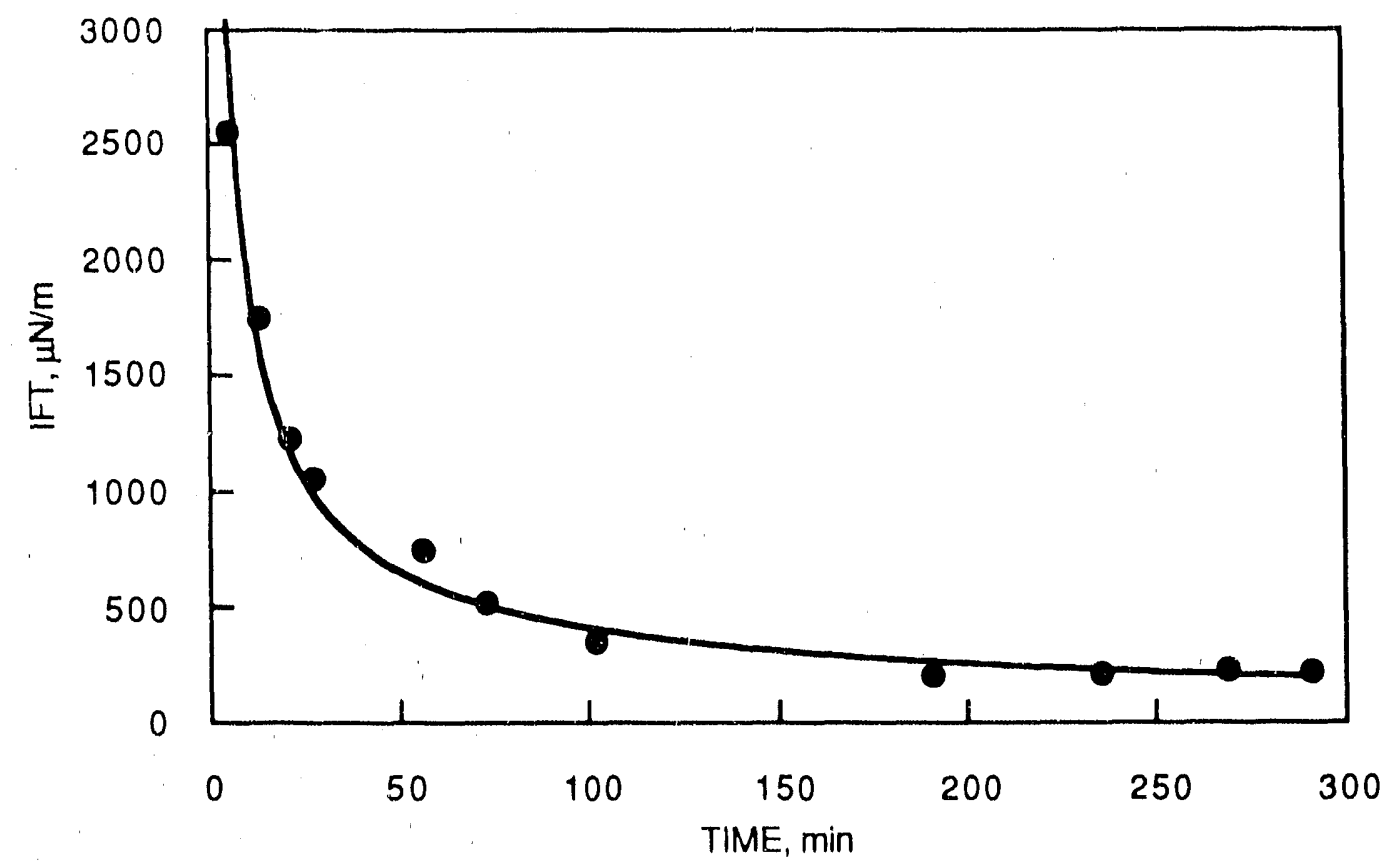

FIGURE 7. Dynamic IFT of Wilmington (CA) Ranger Zone crude oil and $0.1 \%$ Neodol $25-9$ Surfactant.

Phase behavior tests were conducted with Wilmington (CA) crude oil and four commercial surfactants at $\mathrm{pH}$ 8.3. The surfactants tested were Igepon T-33 (sodiurı $\mathrm{N}$-methyl-N-oleoyltaurate), Igepal CA-720 (an octylphenol athoxylate), and Igepal CO-730 and CO-850 (both nonylphenol ethoxylates). The Wilmington oil has an acid number of $1.59 \mathrm{mg} \mathrm{KOH} / \mathrm{g}$ oil and this is, to our knowledge, the first time the Wilmington oil has been tested at $\mathrm{pH} 8.3$ with these particular commercial surfactants.

Many of the samples showed slow water-breakout rates which was encouraging and the lgepon T-33 and Igepal CA-720 series were selected for IFT measurements. The IFT over a salinity range is shown for $0.1 \%$ active Igepon T-33 in fig. 8 . The Igepon T-33 system IFT decreased over the salinity range tested to a low of $17.1 \mu \mathrm{N} / \mathrm{m}$ at $9 \% \mathrm{NaCl}$ concentration. It appears that the optimal salinity is above $9 \% \mathrm{NaCl}$ concentration. The high optimum salinity is interesting but occurs at too high a salinity to be used in the Wilmington field.

In the Igepon T-33 system there was no correlation between the measured IFT values and the results of dynamic phase behavior tests. There was, however, a correlation with the static phase behavior 


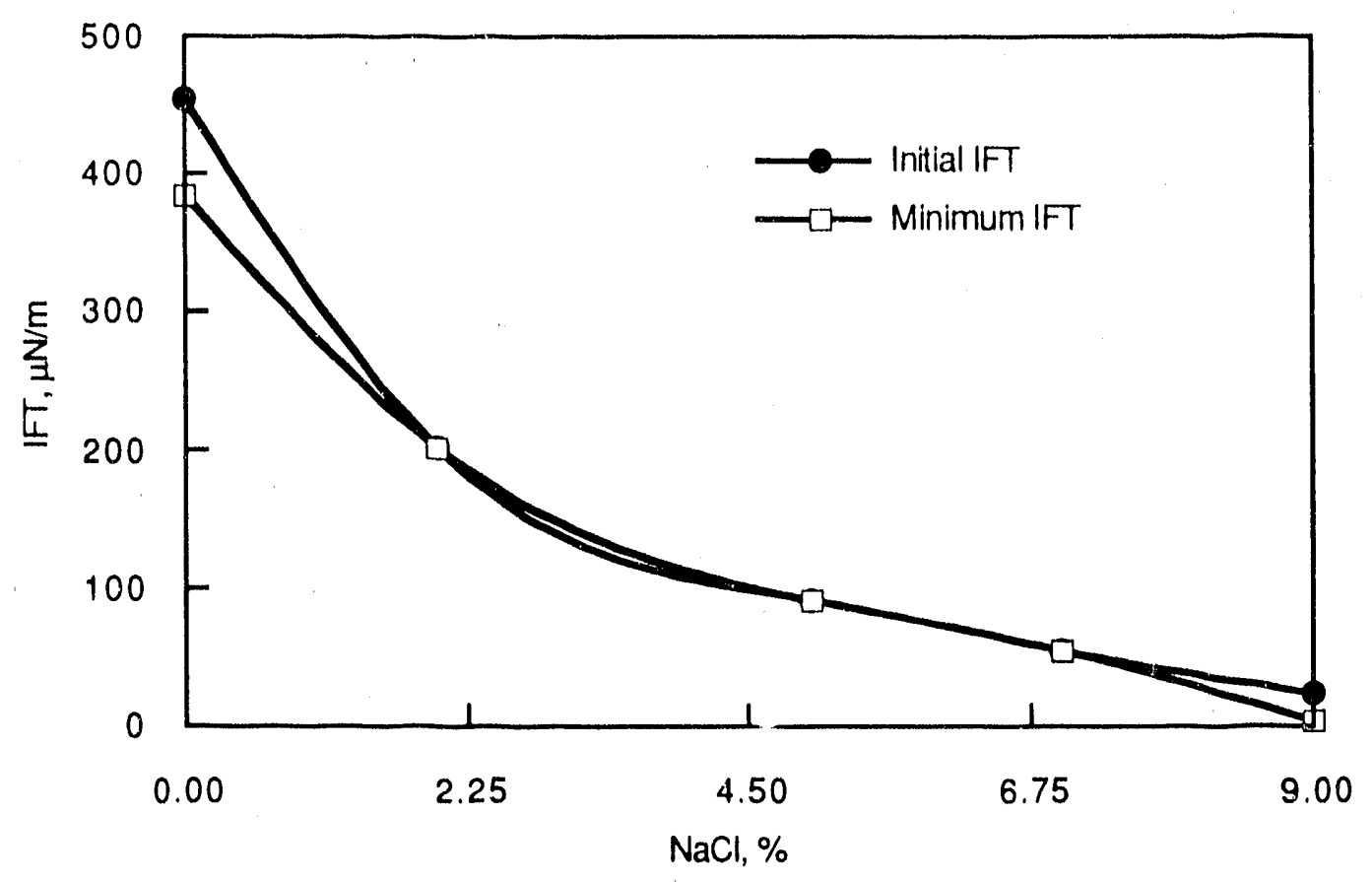

FIGURE 8. Interfacial tension of Wilmington (CA) Ranger Zone crude oil and $0.1 \%$ Igepon T-33 surfactant, $\mathrm{pH} 8.3,52^{\circ} \mathrm{C}$.

tests. At 7 and $9 \% \mathrm{NaCl}$ concentrations, the aqueous and oil phases showed considerable activity at the oil/water interface before the phases were dynamically shaken.

The IFT over a salinity range is shown in fig. 9 for the system formulated at $\mathrm{pH} 8.3$ with lgepal CA-720 surfactant. The IFT behavior of this system was similar to that of the Igepon T-33 described above. The lowest IFT occurred at the highest salinity lested (7\%) and the optimum salinity is probably higher. There was no currelation between the measured IFT values and the results of either dynamic or static phase behavior tests; however, this may be due to the fact that no ultra-low IFT values were obtained with this system. 


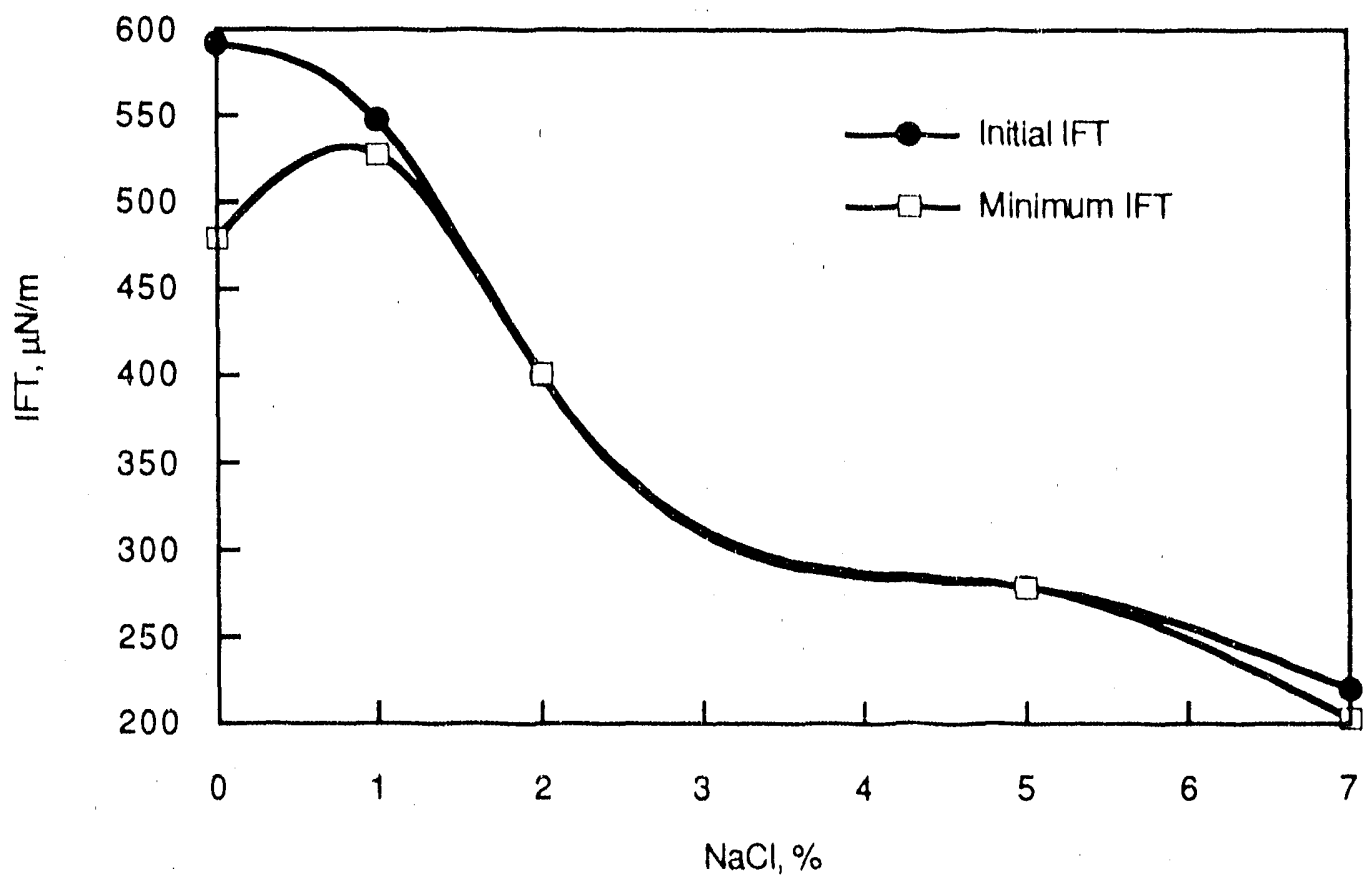

FIGURE 9. Interfacial tension of Wilmington (CA) Ranger Zone crude oil and $0.1 \%$ CA-720 surfactant, $\mathrm{pH} 8,3,52^{\circ} \mathrm{C}$.

\section{Effects of Monohydrogen Phosphate lon Species on IFT and Adsorption}

Carbonate mixtures are effective for removal of calcium ions, and to a lesser extent magnesium ions, from reservoir brines by precipitation reactions. ${ }^{4}$

However, low concentrations of divalent ions still remain in a reservoir after an alkaline preflush. Divalent ions that remain in solution may have deleterious effects which might include degradation of IFT behavior and surfactant loss by precipitation and adsorption.

Between pH 8.5 and $\mathrm{pH} 10.5$, a large fraction of phosphate ions exist in the form of monohydrogen phosphate, which readily complexes cations. ${ }^{10}$ The resultant complexing of calcium and magnesium ions by monohydrogen phosphate may help protect the low concentration of synthetic surfactant used in surfactant-enhanced alkaline floods from the deleterious effect of divalent ions.

The effect of divalent ions on IFT behavior was compared for carbonate and carbonate/phosphate systems. The experiments were conducted at pH 10.5 where most of the phosphate ions exist as the monohydrogen phosphate species. The formulation that included orthophosphate ions contained $0.0104 \mathrm{M} \mathrm{NaHCO}_{3}, 0.0546 \mathrm{M} \mathrm{Na}_{2} \mathrm{CO}_{3}, 0.065 \mathrm{M} \mathrm{Na}_{2} \mathrm{HPO}_{4}$ and $0.051 \mathrm{M} \mathrm{NaCl}$ (ionic strength = 0.140 ). 
The formulation without orthophosphate ions contained $0.0232 \mathrm{M} \mathrm{NaHCO}_{3}, 0.0418 \mathrm{M} \mathrm{Na} 2 \mathrm{CO}_{3}$ and $0.051 \mathrm{M} \mathrm{NaCl}$ (ionic strength $=0.200$ ). The surfactant was $0.1 \%$ Petrostep B-100.

The results of the IFT experiments are shown in table 3. All of the IFT values measured with the orthophosphate-containing solution were lower than the values measured with carbonate only. All of the values were ultralow (below $10 \mu \mathrm{N} / \mathrm{m}$ ) and even the values without divalent lons prese.nt were lower for the orthophosphate-cor caining formulation. This indicates that thie reduction in IFT with the solutions that contained orthophosphate ions is not due to the presence of orthophosphate ions, but instead, reflects an ionic strength that is nearer to optimal.

TABLE 3. - Eifect of monohydrogen phosphate $\left(\mathrm{HPO}_{4} \approx\right.$ ) on the IFT of Wilmington crude oil and weakly alkaline surfactant mixtures, $0.1 \%$ Petrostep B-100 surfactant, $\mathrm{pH} 10.5$

\begin{tabular}{|c|c|c|c|}
\hline Divalent ion & $\begin{array}{c}\text { Divalent ion } \\
\text { concentration, } \mathrm{mg} / \mathrm{L}\end{array}$ & Carbonate mixture & $\begin{array}{c}\text { Phosphate/carbonate } \\
\text { mixture }\end{array}$ \\
\hline \multirow{4}{*}{$\mathrm{Ca}^{++}$} & & Initial IEI $\mu \mathrm{N} / \mathrm{m}$ & Initial IFI $\mu \mathrm{N} / \mathrm{m}$ \\
\hline & 0 & 8.2 & 3.4 \\
\hline & 10 & 7.5 & 5.8 \\
\hline & 1100 & 9.5 & 3.4 \\
\hline \multirow{4}{*}{$\mathrm{Mg}^{++}$} & 0 & 1.6 & 0.1 \\
\hline & 10 & 0.1 & 0.3 \\
\hline & 1100 & 6.7 & 4.0 \\
\hline & & Minimum IFT $\mu \mathrm{N} / \mathrm{m}$ & Minimum IFI $\mu \mathrm{N} / \mathrm{m}$ \\
\hline \multirow[t]{3}{*}{$\mathrm{Ca}^{++}$} & 0 & 2.8 & 2.4 \\
\hline & 10 & 7.5 & 3.4 \\
\hline & 1100 & 9.5 & 2.3 \\
\hline \multirow[t]{3}{*}{$\mathrm{Mg}^{++}$} & 0 & 1.6 & 0.1 \\
\hline & 10 & 0.1 & 0.1 \\
\hline & 1100 & 0.1 & 0.3 \\
\hline
\end{tabular}

Concentration exceeds the solubility limit.

Therefore, it was concluded that orthophosphate ions do not reduce the deleterious effects of divalent ions on IFT behavior in carbonate solutions where the deleterious effect of divalent ions is already so low that it is nearly absent. It also indicates that the precipitation reactions of carbonate mixtures provide adequate mitigation of the divalent ion effects in weakly alkaline surfactant solutions.

The effect of orthophosphate on surfactant loss was measured in bottle tests conducted with 250 to $425 \mu \mathrm{m}$ crushed Berea. These experiments were conducted at $\mathrm{pH} 9.5$ and with constant ionic strength. The alkaline solutions were $0.095 \mathrm{M} \mathrm{NaHCO}_{3}+0.0475 \mathrm{M} \mathrm{Na}_{2} \mathrm{CO}_{3}$ (ionic strength $=0.238$ ) and $0.053 \mathrm{M} \mathrm{Na}_{2} \mathrm{HPO}_{4}+0.0127 \mathrm{M} \mathrm{Na}_{2} \mathrm{CO}_{3}+0.0402 \mathrm{M} \mathrm{NaHCO}_{3}$ (ionic strength = 0.237 ). The surfactant was $0.1 \%$ Petrostep B 100 . 
TABLE 4. - Effect of monohydrogen phosphate $\left(\mathrm{HPO}_{4}=\right.$ ) on the adsorption of Petrostep B-100 surfactant in weakly alkaline mixtures, $\mathrm{pH} 9.5$

\begin{tabular}{|c|c|c|c|}
\hline \multirow{2}{*}{$\begin{array}{c}\mathrm{Mg}^{++} \text {Conceniration, } \\
\mathrm{mg} / \mathrm{L}\end{array}$} & \multicolumn{2}{|c|}{ Adsorption, meq/kg } & Reductio $11, \%$ \\
\hline & Carbonate mixture & $\begin{array}{c}\text { Phosphate/Carbonate } \\
\text { mixture }\end{array}$ & \\
\hline $\begin{array}{r}0 \\
10 \\
100 \\
\end{array}$ & $\begin{array}{l}0.878 \\
0.900 \\
1.134 \\
\end{array}$ & $\begin{array}{l}0.566 \\
0.570 \\
0.834\end{array}$ & $\begin{array}{l}35.5 \\
36.7 \\
26.5\end{array}$ \\
\hline
\end{tabular}

The results are shown in table 4. Magnesium concentration was varied from 0 to $100 \mathrm{ppm}$, a level at which magnesium solubility at these conditions is exceeded. The results showed no correlation between the amount of reduction in surfactant loss in the presence of monohydrogen phosphate lons and the magnesium ion level. However, overall surfactant adsorpiion was reduced about $30 \%$ by the presence of orthophosphate. This leads to the possibility that simple phosphate icn species, as well as polyphosphates, can significantly reduce surfactant loss.

\section{Surfactant Transport in Porous Media}

Surfactant-enhanced alkaline flooding with weak alkaline agents is effective for recovery of crude oils from a variety of reservoirs. An objective of project BE4B in FY90 was to develop cost-effective alkaline flooding formulations with surfactants that are readily available. The formulation of systems that provide for transport of the surfactant deep into the reservoirs was of prime importance.

This year, the study of the transport of an EOR surfactant through oil-free Berea cores was continued. The surfactant used was Petrostep B-100, an EOF surfactant designed for use in bw-tension flooding. In FY89, the rate at which this surfactant is transported through cores was investigated. It was concluded that the rate of transport of this surfactant was improved by increasing temperature, permeability and $\mathrm{pH}$, and by decreasing total ionic strength.

In the corefloods performed in FY89, $\mathrm{pH} 10.2$ or $\mathrm{pH} 6.3$ chemical slugs containing $0.1 \%$ surfactant were followed by $\mathrm{pH} 6.3$ chase brine. Total adsorption was $50 \%$ lower when the chemical slugs were injected at $\mathrm{pH} 10.2$ than when injected at $\mathrm{pH}$ 6.3. In addition to the lower adsorption at higher $\mathrm{pH}$, a second surfactant peak appeared in the $\mathrm{pH} 10.2$ coreflood effluent about $1 \mathrm{PV}$ after changing to the lower ionic strength chase brine. ${ }^{12}$

Filtration experiments showed that this effect was probably due to a decrease in the size of the surfactant aggregates as the chase brine, which was at a lower total ionic strength, passed through the core. This hypothesis was confirmed this year by performing an additional coreflood with a different injection sequence. 
In this coreflood, the pH 10.2 chemical slug was followed by a pH 10.2 chase solution of the same total ionic strength. After injection of 3.91 PV of the chase solution, 2.97 PV of the lower ionic strength sodium chloride brine was injected. The results are shown in figure 10. There was not a second surfactant peak during injection of the chase solution. However, a second surfactant peak did appear about 1 PV after injection of the lower lonic strength brine was started.

The results of this experiment confirmed the previous conclusion that total ionic strength has an effect on the rate at which this surfactant is transported through porous media. Total surfactant retention in the core was $0.180 \mathrm{meq} / \mathrm{kg}$, which is comparable to the retention in the previous experiments pertormed with pH 10.2 chemical slugs, and $50 \%$ lower than retention in the experiment frerformed with a $\mathrm{pH} 6.3$ chemical slug.

\section{()BSERVATIONS AND CONCLUSIONS}

1. Surfactant-enhanced alkaline flooding does have merit for use with low-acid crude oils. However, each oll behaves differently, and applicability must be determined for each oil.

2. Orthophosphate did not appear to further reduce the deleterious effect of divalent ions on IFT behavior in carbonate solutions, where the deleterious effect of the divalent ions is already very low.

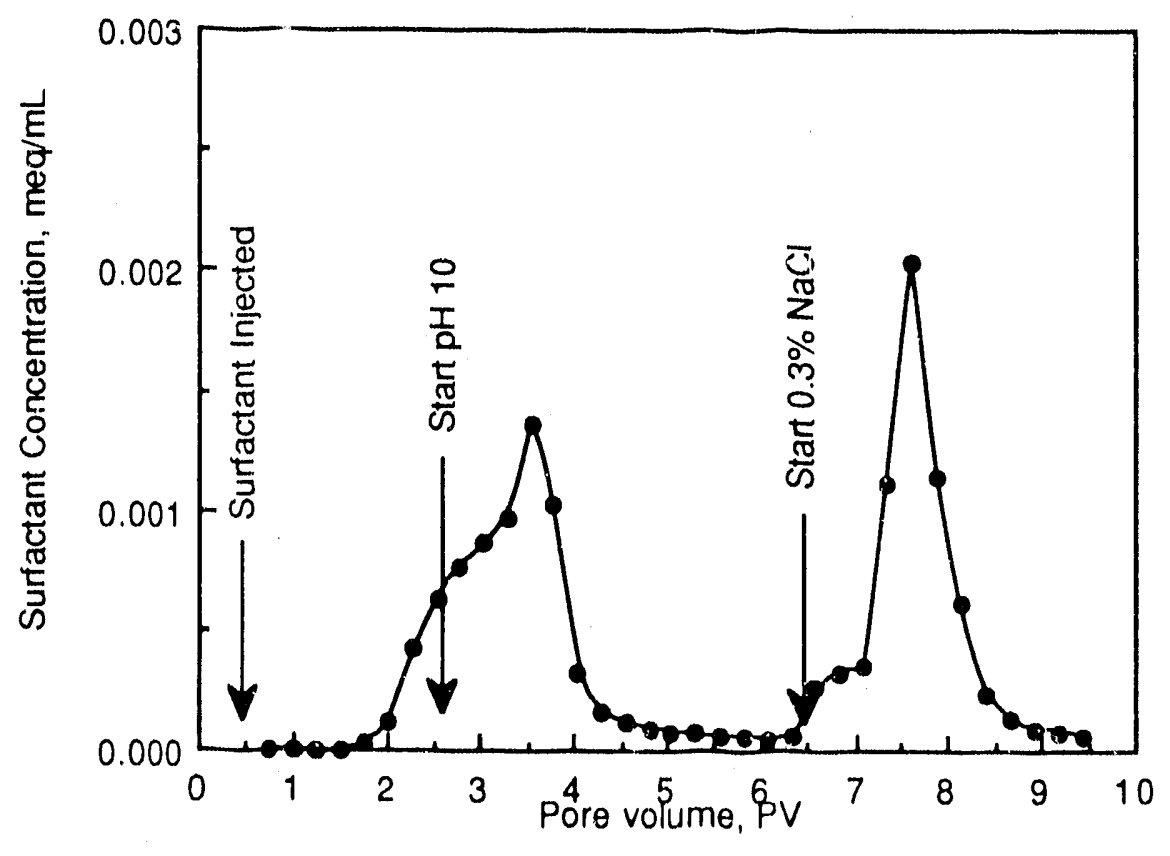

FIGURE 10. Surfactant transport in an oil-free Berea sandstone core. 
3. Orthophosphate substantlally reduced adsorption of an anionlc surfactant; however, there was no correlation between the amount of reduction and divalent lon levels.

4. Orthophosphate additive in alkaline formulations is an additional source of alkalinity.

5. A.lkaline/surfactant formulations must be very carefully designed to minimize the loss of surfactant as aggregates that are formed at the high ionic strength of some alkaline formulations.

6. A variety of surfactants are avallable commercially that have potential for use between $\mathrm{pH} 8.3$ and $\mathrm{pH}$ 9.5 in Wilmington (CA) field.

\section{REFERENCES}

1. Lorenz, F'.B. and D.A. Peru. Guidelines Help Select Reservoirs for NaHCO3 EOR. Oll \& Gas J., V. 87, No. 37, Sept. 11, 1989, pp. 53-57.

2. Enhanced Recovery Weok, June 16, 1986.

3. Clark, S.R., I.M. Pitts, and S.M. Smith. Design and Application of an Alkaline-Surtactant-Polymer Recovery System to West Kiehl Field. Presented at the Soc. Pet. Eng. Rocky Mountain Regional Meeting, May 1988. SPE paper 17538.

4. Enhanced Recovery Week, June 15, 1987.

5. Peru, D.A. Aqueous Flooding Methods for Tertiary Oil Recovery. U. S. Patent 4,817,715, April 1989.

6. French, T.R., D.A. Peru, and S.D. Thornton. Low pH Alkaline Chemical Formulations. Dept. of Energy Report No. NIPER-375, October 1988.

7. Labrid, J. and B. Bazin. Alkaline Preflush in a Low-Permeability Clayey Sandstone. J. Pet. Sci. Eng., v. 3, 1989, pp. 111-120.

8. Krumrine, P.H., J.S. Falcone, Jr., and T.C. Campbell. Surfactant Flooding 1: The Effect of Alkaline Additives on IFT, Surfactant Adsorption, and Recovery Efficlency. Soc. Pet. Eng. J., v. 22, No. 4 , August 1982. 
9. Holm, L.W. and S.D. Robertson. Improved Mict lar/Polymer Flooding with High-pH Chemicals. J. Pet. Tech., vol. 33, Jaruary 1981, pp. 161-172.

10. Strumm, W. and James J. Morgan. Aquatic Chemistry. Wiley-Interscience, New York, London, Sydney, and Toronto, 1970.

11. Van Wazer, J.R. Phosporous and Its Compounds. Interscience Publishers, Inc., New York and London, 1958.

12. French, T.R. Design and Optimization of Phosphate-Containing Alkaline Flooding Formulations. Dept of Energy Report No. NIPER-446, September 1989.

13. Nelson, R.C., J.B. Lawson, D.R. Thigpen, and G. L. Stegemeier. Cosurfactant-Enhanced Alkaline Flooding. Pres. at the Fourth Joint SPE/DOE Symposium on Enhanced Oil Recovery, Tulsa, OK, Apr. 16-18, 1984, SPE/DOE paper 12672.

14. Wasan, D.T. Enhanced Oil Recovery Through in Situ Generated Surfactants Augmented by Chemical Injection. Illinois Institute of Technology Annual Report, 1989.

15. Rosen, M.J. and H.A. Goldsmith. Systematic Analysis of Surface Active Agents. WileyInterscience, New York, 1972, pp. 423-424.

16. Hotman, Y.L. and H.P. Angstadt. Analysis of Enhanced Oil Recovery Formulations. Chromatographia, v. 24, 1987, pp. 666-679.

17. French, T.R. The Effect of Alkaline Additives on the Performance of Surfactant Systems Designed To Recover Light Crude Oils. To be published.

18. French, T.R. and T.E. Burchfield. Design and Optimization of Alkaline Flooding Formulations. Pres. at the Seventh Joint SPE/DOE Symposium on Enhanced Oll Recovery, Tulsa, OK, April 1990, SPE/DOE paper 20238.

19. Olsen, D.K., M.D. Hicks, and B.G. Hurd. Design of a Novel Flooding System for an Oil-Wet Central Texas Carbonate Reservoir. Pres. at the Seventh Joint SPE/DOE Symposium on Enhanced Oil Recovery, Tulsa, OK, April 1990, SPE/DOE paper 20224. 

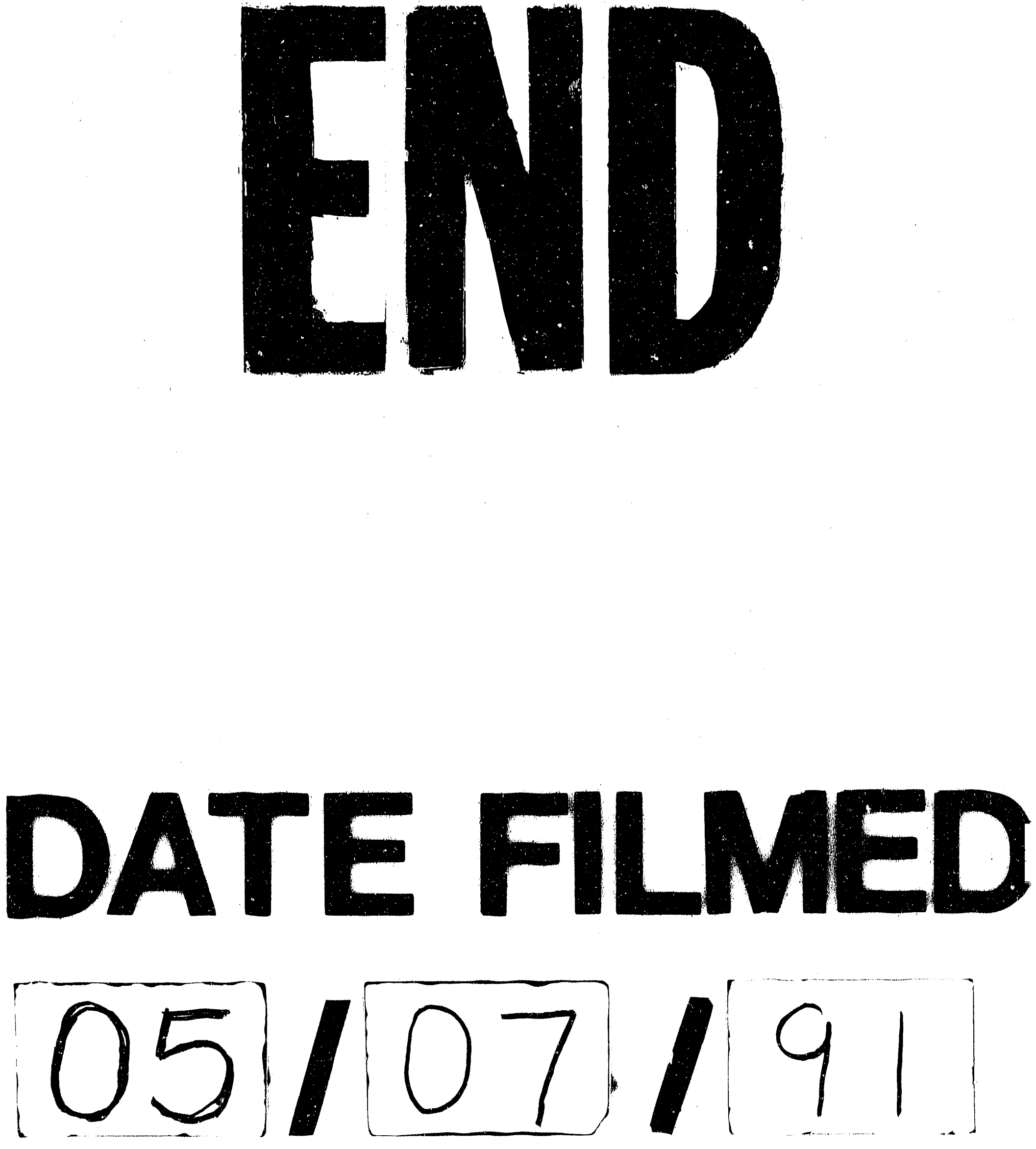